\title{
Validation of the HADS and PSS-10 and psychological status in patients with oral lichen planus
}

Paswach Wiriyakijja ${ }^{1,2 *}$, Stephen Porter ${ }^{1}$, Stefano Fedele ${ }^{1,3}$, Tim Hodgson $^{4}$, Roddy

McMillan $^{4}$, Martina Shephard ${ }^{4}$, Richeal Ni Riordain ${ }^{1,5}$

\author{
${ }^{1}$ UCL Eastman Dental Institute, London, United Kingdom \\ ${ }^{2}$ Department of Oral Medicine, Faculty of Dentistry, Chulalongkorn University, Bangkok, Thailand \\ ${ }^{3}$ NIHR University College London Hospitals Biomedical Research Centre, London, United Kingdom \\ ${ }^{4}$ Eastman Dental Hospital, UCLH Foundation NHS Trust London, London, United Kingdom \\ ${ }^{5}$ Department of Oral Medicine, Cork University Dental School and Hospital, Cork, Ireland. \\ ${ }^{*}$ Corresponding author. \\ E-mail address: paswach.w@gmail.com
}

Running title: Psychological status in OLP

Key words: Oral lichen planus; Hospital anxiety and depression scale; Perceived stress scale; Factor analysis; Anxiety; Depression 


\section{ABSTRACT}

Objectives: To validate the Hospital Anxiety and Depression Scale (HADS) and the 10-item Perceived Stress Scale (PSS-10) for use in patients with oral lichen planus (OLP) and to provide cross-sectional analysis of anxiety, depressive and distress symptoms in patients with OLP.

Methods: Validity and reliability of both instruments were assessed in 260 participants with OLP in one tertiary Oral Medicine Centre through confirmatory factor analysis and calculation of reliability coefficients. Prevalence, Clinical and demographic predictors of the presence of psychological symptoms in OLP were calculated and identified using multivariated logistic regression.

Results: Factor analysis results demonstrated that a bifactor model described the underlying structure of both scales better than other models. Values of omega indicated adequate reliability of total HADS and PSS-10 score while low coefficient omega hierarchical values limit clinical applicability of their subscale scores. The prevalence of anxiety, depressive and distress symptoms in OLP were $39.23 \%$, $20.77 \%$ and $27.69 \%$ respectively. Pain intensity, disease comorbidities, age, smoking and alcohol consumption were found to be independent predictors of the presence of psychological symptoms in OLP.

Conclusion: The HADS and PSS-10 are appropriate to use as general measures of psychological distress and perceived stress in patients with OLP. 


\section{Introduction}

Oral lichen planus (OLP) is a common chronic immune-mediated inflammatory condition that can cause persistent ulceration of the oral mucosa (Eisen, Carrozzo, Bagan Sebastian, \& Thongprasom, 2005). The disease is also associated with a small increased risk of oral cancer development (Giuliani et al., 2019). Oral ulceration of OLP can give rise to varying degrees of oral pain and discomfort, and affected patients frequently experience notable impairment of eating, oral hygiene care and speech. They can also experience considerable changes in their psychological status due to the chronicity and unpredictable clinical behaviour of the disease, as well as the increased risk of oral cancer development (Ni Riordain, Meaney, \& McCreary, 2011). Despite its negative impact on psychological well-being, the psychosocial burden of OLP upon patients is often underestimated, overlooked, and/or sub-optimally managed by clinicians who may lack experience in assessing the biopsychosocial aspects of this oral condition.

A number of studies, including a recent systematic review, suggested that levels of various psychological morbidities including anxiety, depressive symptoms, perceived stress and sleep disturbance were found to be higher in patients with OLP than in healthy individuals (Adamo et al., 2015; Cerqueira et al., 2018; Eisen, 2002; Vallejo, Huerta, Cerero, \& Seoane, 2001). Interestingly, a recent study found that psychological changes in patients with OLP may be preceded by sleep disturbance due to a positive association between poorer sleep quality and greater level of anxiety and depressive symptoms in patients with OLP (Adamo et al., 2015). These changes in psychological status of affected patients may influence the onset and periods of exacerbation of OLP. Painful oral symptoms together with the psychosocial impact of 
OLP could lead to a poor overall oral health-related quality of life of affected patients (Tadakamadla, Kumar, Lalloo, \& Johnson, 2017). A recent comprehensive review found that a wide variety of psychological outcome measures have been used in clinical studies and trials of OLP for the evaluation of anxiety, depression and stress, with the most frequently used instruments being the Hospital Anxiety and Depression Scale and the 10-item Perceived Stress Scale (Wiriyakijja, Fedele, Porter, Mercadante, \& Ni Riordain, 2018).

The Hospital Anxiety and Depression Scale (HADS) is a 14-item self-report questionnaire, initially designed as a screening measure of anxiety and depression in non-psychiatric hospital patients, without items reflecting physical health problems e.g. headaches, insomnia, dizziness and anergia (Zigmond \& Snaith, 1983). The HADS developers proposed the scale as a two-factor scale measuring anxiety and depression separately. However, content validity of the HADS appears to be somewhat questionable (Coyne \& van Sonderen, 2012). Due to the omission of somatic symptoms and its narrow focus towards only cognitive and emotional components of anxiety and depression (e.g. anhedonia, the inability to feel pleasure), the construct measured by the scale does not comprehensively and accurately cover the diagnostic criteria for generalized anxiety disorders and major depressive disorders. In addition, there is currently ongoing debate among experts regarding the scale's underlying dimensionality and its ability to distinguish between anxiety and depression, both of which are commonly comorbid and often difficult to distinguish (Cosco, Doyle, Ward, \& McGee, 2012).

The 10-item Perceived Stress Scale (PSS-10) is a self-report scale developed to assess perceived stress level in the general population (Cohen, Kamarck, \& Mermelstein, 1983). Conceptually, the PSS-10 measures the degree to which 
situations over the last month in the respondent's life are appraised as unpredictable, uncontrollable and overloading. The PSS-10 was originally designed to be a unidimensional measure of perceived stress but psychometric evidence from subsequent studies revealed the existence of two subscales in the PSS-10 comprising perceived stress subscale (6 negatively phrased items) and perceived self-efficacy subscale (4 positively phrased items) (Nielsen et al., 2016). Similar to the HADS, there remains no consensus regarding the underlying structure underpinning the PSS-10 (E. H. Lee, 2012). Despite mixed evidence supporting structural validity of the HADS and PSS-10, both instruments continue to be extensively used across a spectrum of medical conditions including cancer and cardiovascular diseases, with wellestablished normative data in various populations (Norton, Cosco, Doyle, Done, \& Sacker, 2013). Once these patient-reported measures have been properly validated, they have been proven to be useful, user-friendly and appropriate psychological measures in both clinical and research settings.

Factor structure and psychometric robustness of both instruments, however, has yet to be fully explored in patients with OLP, which raises the question whether the HADS and PSS-10 are valid, reliable and appropriate outcome measures for use in the management of such patients. The primary aim of the present study was to examine psychometric properties including structural validity and internal consistency reliability of the HADS and PSS-10 in a sample of patients with OLP. The secondary objective of this study was to evaluate the association between psychological comorbidities and associated demographic and clinical factors in this patient population. Using a crosssectional quantitative approach, the predefined hypotheses were as follows; Demographic factors and clinical variables including types, disease severity, symptom 
intensity of OLP and presence of extraoral lichen planus were associated with the presence of anxiety, depressive and distress symptoms in OLP.

\section{Methods}

\section{Study design}

This was a cross-sectional, secondary analysis of baseline data from the Determination of Minimal Important Difference and Patient Acceptable Symptom State of Patient Reported Outcome Measures in Immunologically mediated Oral Mucosal Diseases (MEAN-IT) study, which was approved by the London - Queen Square Research Ethics Committee (REC reference 17/LO/1825; approval date 3 November 2017).

\section{Participants}

The study participants comprised 260 patients with oral lichen planus attending regular review appointments at the Oral Medicine clinic, UCLH Eastman Dental Hospital, London, United Kingdom. Participant recruitment was based upon a convenience sampling. All potentially eligible participants, in all Consultant lead Oral Medicine clinics between January 2018 and June 2019 were invited to participate (conducted by PW). All participants provided written informed consent to participate in the study. The inclusion criteria were patients with clinical and histopathologically-confirmed OLP based upon modified WHO diagnostic criteria (van der Meij \& van der Waal, 2003). The exclusion criteria were as follows: (a) evidence of oral epithelial dysplasia in the biopsy specimen; (b) evidence of proven hypersensitivity to dental restorative materials; (c) evidence of oral lichenoid lesions associated with graft-versus-host disease and systemic lupus erythematosus; (d) coexisting chronic neuropathic orofacial pain such as burning mouth syndrome, persistent idiopathic facial pain and 
trigeminal neuropathic pain; (e) patient-reported significant underlying systemic conditions (ASA 3 or more) and/or some psychiatric illnesses as defined by DSM-5, which might interfere with study participation such as Parkinson's disease, Alzheimer's disease and schizophrenia; (f) inability to read English language and understand questionnaires. Patients with known concomitant anxiety and depression or those currently used psychotropic drugs were not excluded in the present study in order to ensure real-world population of OLP patients with these psychological comorbidities was represented. Of a final sample of 260 participants, no participant was excluded in case of missing data.

\section{Sample size calculation}

The sample size was in line with recommendation from the COnsensus-based Standards for the selection of health Measurement Instruments (COSMIN) Risk of Bias checklist, which stipulates that a sample size for a factor analysis study should include at least 100 and more than 7 times the number of items of the outcome measures examined (at least 98 and 70 for factor analysis of the HADS and PSS-10, respectively).

\section{Procedure}

A comprehensive oral examination was carried out on all study participants (performed by PW) to assess the clinical type, oral sites of involvement and disease activity using the Oral Disease Severity Score. Participants were then asked to complete a demographic form and a set of patient-reported outcome measures including the visual analog scale (VAS) for pain, the numerical rating scale (NRS) for pain, the HADS and the PSS-10. Information regarding disease duration (time since symptom onset), presence of extra-oral OLP, past medical history, social history, and current 
management of OLP was obtained from review of electronic patient records. The present study was reported in accordance with the Strengthening the Reporting of Observational Studies in Epidemiology (STROBE) guidelines (Appendix) (Von Elm et al, 2007).

\section{Outcomes and outcome measures}

The primary outcome for the secondary objective of the present study was the presence of psychological morbidities as measured by the HADS and PSS-10. Demographic variables that may have contributed to the presence of psychological comorbidities including age, gender, ethnicity, smoking, alcohol consumption and systemic comorbidities were recorded. Potential associated clinical factors including types, symptom intensity, disease duration and severity of OLP and presence of extraoral lichen planus were also recorded.

Clinical scoring

The Oral Disease Severity Score (ODSS) is a validated clinical scoring system for the measurement of the severity of oral mucosal conditions including OLP (Escudier et al., 2007). The ODSS assesses the presence and extent of mucosal lesions as well as the severity of clinical presentations in 17 oral subsites. A total score is calculated by the summation of clinician-assessed site and activity scores with a 0-10 verbal rating scale for average oral pain over the past 2 weeks, with theoretical combined scores ranging from 0 to 106 . Clinical sensitivity and inter-rater reliability were found to be adequate for use in the OLP population.

Patient-reported outcome measures

The Visual analog scale (VAS) for pain is a measure of pain intensity comprising a 100-mm horizontal line, labeled with 'no pain' at one end and 'worst pain imaginable' 
on the other end. Participants were asked to place a perpendicular mark on the point of the line that best reflected the degree of pain they were currently experiencing from OLP.

The Numerical Rating Scale (NRS) for pain is a segmented numeric version of the VAS for pain. Participants were asked to select one whole number from 0 to 10 (11point scale) that best reflected the intensity of the current oral pain they were experiencing from OLP. Both the VAS and NRS have been investigated for construct validity and the findings showed psychometric adequacy for use in the OLP population (Chainani-Wu et al., 2008).

The Hospital Anxiety and Depression Scale (HADS) is a brief screening measure of anxiety and depression through 14 items, consisting of a 7-item anxiety (HADS-A) and a 7-item depression (HADS-D) subscale. The HADS-A subscale includes items concerning generalized symptoms of anxiety e.g. feelings of tension, fear, worry and panic while the items on the HADS-D subscale largely focus upon anhedonia (loss of pleasure), a cardinal symptom of depression. For each item, participants were asked to rate items according to how they had felt in the past week on a 4-point Likert-type scale (0-3), with the total subscale score ranging from 0 to 21 in each subscale. Higher scores denote greater intensity of anxiety or depressive symptoms. A cut-off HADS-A or HADS-D score of 8 or above is indicative of the presence of anxiety and depression (Bjelland, Dahl, Haug, \& Neckelmann, 2002), and the HADS total (HADS-T) score of 15 or over indicates the presence of emotional distress (Schellekens et al., 2016).

The 10-item Perceived Stress Scale (PSS-10) is a 10-item self-report measure of stress appraisal. Participants were asked to stipulate how often they experienced a particular thought or feeling during the preceding month on a 5-point Likert scale from 
never (0) to very often (4). Six items of the PSS-10 are negatively phrased (item 1, 2, $3,6,9,10$; negative perception subscale) while the remaining four (item $4,5,7,8$; positive perception subscale) are positively phrased items and require reverse coding. Total PSS-10 score was calculated by summing scores across all the items, providing a total score range of $0-40$. A higher score represents greater perceived stress. As the PSS-10 is not a diagnostic tool, there are no cut-off scores.

\section{Data analysis}

Statistical analyses were carried out using STATA version 15.1 (StataCorp, College Station, TX, U.S.A.) and MPlus version 8.2 (Muthén \& Muthén, 2015). Preliminary item analyses were performed to examine median, interquartile range (IQR), score distribution statistics (skewness, kurtosis) as well as floor and ceiling effects ( $>15 \%$ of participants endorsing the lowest and highest possible option, respectively) of each item in the HADS and PSS-10 (Terwee et al., 2007). Descriptive analyses for demographic and OLP-related characteristics were summarized using frequencies and percentages for categorical variables, and as the majority of continuous variables were non-normally distributed from the histogram and the Shapiro-Wilk test, median and interquartile range (IQR) were used as summary statistics. Mean, standard deviation and range were also shown for comparison with previous studies.

Structural validity of the HADS and PSS-10 was examined through confirmatory factor analysis (CFA) to test whether the data from the OLP population fit the previously proposed factor structures of both scales. Without sufficient evidence supporting structural validity, measurements cannot be adequately interpreted. A mean- and variance-adjusted weighted least square (WLSMV) estimator was applied to test the covariance matrix for the CFA (Beauducel \& Herzberg, 2006; Millsap \& Yun-Tein, 
2004). Four CFAs were performed to test the fit of the HADS data with the four most commonly identified factor structures including the uni-dimensional distress model, the original two-factor model, the three-factor non-hierarchical model of anxiety, depression and negative affectivity proposed by Dunbar et al (2000) and the bi-factor model (Figure 1). To test factor structures of the PSS-10 in the OLP population, three CFAs were used to test the fitness of OLP data with the following hypothesized models: one-, two- and bi-factor model (Figure 1). The bi-factor model allows all the items to load on a general factor reflecting unidimensionality of the scale, and in addition, onto specific group factors indicating multidimensionality of the scale. Acceptability of model fit was assessed by the use of fit indices including root mean square of error approximation (RMSEA), standardized root mean squared residual (SRMR), comparative fit index (CFI) and Tucker-Lewis index (TLI). RMSEA and SRMR values closer to 0 indicate better fit, with values below 0.08 and 0.05 indicating acceptable and good fit, respectively. CFI and TLI values greater than 0.95 are considered acceptable (Hu \& Bentler, 1999).

Cronbach's alpha coefficients were computed to assess internal consistency reliability of both total and subscale scores of the HADS and PSS-10 based upon the best fitted model from the CFA results. Internal consistency reliability is the degree to which items within a scale are interrelated and thus reliably measure the underlying concept of interest, and Cronbach's alpha $(\alpha)$ of at least 0.70 was considered acceptable (Mokkink et al., 2010; Terwee et al., 2007). For the bi-factor models, two additional variance-based reliability indices, which are considered superior to a for a multidimensional construct, were computed including McDonald's omega coefficient $(\omega)$ and coefficient omega hierarchical $(\omega-h)$. The $\omega$ computes bifactor-model-based reliability of the total score combining variance from both general and specific group 
factors while the $\omega$-h estimates reliability of summed scores explained by only one construct with all other factor variance removed (Brunner, Nagy, \& Wilhelm, 2012; Zinbarg, Revelle, Yovel, \& Li, 2005). For the general factor, the difference between $\omega$ and $\omega$-h demonstrates reliability of the total score attributable to specific factors after controlling for a general factor. High coefficient $\omega$-h $(>0.8)$ indicates that total score can be considered unidimensional. For the specific group factor, $\omega$-h reflects capacity of a subscale score to reliably measure the underlying factor variance by itself, and low $\omega$-h values deter the use of subscale scores. Both omega coefficients were calculated using the omega software (Watkins, 2013). Regardless of factorial structure and results of psychometric analysis, a cross-sectional analysis of psychological profile of patients with OLP was demonstrated based upon the originally proposed structure of both scales for a comparison with previous studies.

For the purpose of cross-sectional analysis, participants were dichotomized by the presence/absence of anxiety, depressive and emotional distress symptoms using the following cut-off scores of self-report outcome measures: 8 for the HADS-A, 8 for the HADS-D and 15 for the HADS-T, respectively. To identify potential predictors of anxiety, depressive and psychological distress symptoms in the OLP population, bivariate analysis between subgroups was conducted using the chi-square or Fisher's exact tests for categorical variables as appropriate while Mann-Whitney $U$ test or independent sample t-tests were performed for comparisons of medians and means of continuous variables between subgroups respectively. All tests were two-tailed and a p-value of less than 0.05 was considered statistically significant. Variables with statistical significance from bivariate analysis were entered into univariate logistic regression, and the crude odds ratio (OR), 95\% confidence interval $(\mathrm{Cl})$ and $\mathrm{p}$-value were calculated. Each of the demographic and OLP-related variables with a p-value 
of less than 0.1 on univariate analyses were then entered into separate multivariate logistic regression models using a forward stepwise procedure. Each of the explanatory variables was adjusted for the same set of variables (listed below in the results section). Adjusted odds ratios (Adj-ORs) with $95 \% \mathrm{Cl}$ for each independent variable were calculated.

\section{Results}

\section{Descriptive item analyses}

Descriptive item score statistics, response distribution and score distribution indices (skewness and kurtosis) for the HADS and PSS-10 are summarized in Table 1. The score distribution for the lowest response options ranged from $16.15 \%$ to $38.85 \%$ for the HADS-A items, between $18.08 \%$ to $73.08 \%$ for the HADS-D items and between $7.69 \%$ to $30.38 \%$ for the PSS-10 items. All skewness values of both scales were positive except for item P3 of the PSS-10, implying a long distribution tail towards larger values than the mean (positive skew). No ceiling effects were observed but all items of the HADS and seven PSS-10 items showed floor effects.

\section{Confirmatory factor analysis}

The goodness-of-fit indicators of four HADS and three PSS-10 confirmatory factor analysis models are displayed in Table 2. For the HADS CFA results, one-factor model provided a poor fit to the OLP data according to RMSEA value and was thus rejected. Both the original 2-factor and 3-factor models had acceptable-to-good level of fit indices, and only slight improvement in model fit statistics was observed in the 3-factor model in comparison with the 2-factor model. Notably, the bifactor model was found superior to other tested models in all fit statistics $(\mathrm{RMSEA}=0.051, \mathrm{SRMR}=0.035$, $\mathrm{CFI}=0.989, \mathrm{TLI}=0.984)$ and was the only model which demonstrated good 
acceptability threshold of SRMR $(<0.05)$, supporting its utility to better explain the HADS results in the OLP population. As for the PSS-10, RMSEA values did not reach critical value of 0.08 , indicating poor model fit of the original 1 -factor and 2 -factor models though other fit indices were found acceptable. Similar to the HADS, the bifactor model outperformed other tested models in all goodness-of-fit statistics $(\mathrm{RMSEA}=0.076, \mathrm{SRMR}=0.021, \mathrm{CFI}=0.991, \mathrm{TLI}=0.984)$.

\section{Reliability}

Since the CFA results revealed the bifactor model as the best fitting latent structure of the HADS and PSS-10, reliability estimates of total and subscale scores of both scales including Cronbach's $\alpha$, McDonald's $\omega$, and coefficient $\omega$ hierarchical were computed and shown in Table 3. The conventional Cronbach's $\alpha$ values of all total scales and subscales were in the acceptable range, reflecting adequate internal consistency reliability of the scales. Regarding the bifactor model-based reliability, McDonald's $\omega$ coefficients of general factor and specific group factors of both HADS and PSS-10 were satisfactory. High $w$-h of total HADS and PSS-10 scores indicated general distress factor and general stress factor accounted substantially for composite score variance of the HADS (0.838) and the PSS-10 (0.88) respectively, and this supported the utility of overall HADS and PSS-10 scores. However, low range of $\omega$-h values in all subscale scores of both scales indicated that reliability variance of subscale scores after controlling for influence from general factor is considerably low $(<0.3$ in all subscales), and the use of subscale scores of the HADS and PSS-10 in the OLP population should be done with caution.

\section{Demographic and clinical characteristics of study participants}


The demographic and clinical characteristics of the 260 study participants are summarized in Table 4. The proportion of females was higher than that of males with a ratio of $4: 1$ ( $80 \%$ Female). The mean age of OLP patients was $63.32 \pm 11.22$ years (range: 27-88 years). The median OLP disease duration was about 6 years. Based upon the ODSS record form, atrophic/erosive OLP was the most common clinical variant in this sample (44.62\%). Approximately one quarter of patients had at least one site of extraoral involvement, and genitalia (17.31\%) and skin (14.23\%) were the two most frequently coexisting sites of lichen planus involvement in this sample. The vast majority of patients (85\%) had at least one disease comorbidity, and the most frequent systemic conditions were hypertension (33.85\%), hypercholesterolaemia (18.08\%), osteoarthritis (15\%), diabetes mellitus (11.92\%) and hypothyroidism (10.38\%). Topical corticosteroids were the most frequently prescribed treatment for OLP $(63.08 \%)$ in this sample.

Bivariate analysis of demographic and OLP-related variables by the presence of anxiety symptoms, depressive symptoms and psychological distress are presented in Table 4. All the statistically significant variables including patient's age (continuous variable), ethnicity, history of smoking and alcohol consumption, number of comorbidities, disease duration (short and long disease duration using arbitrary cutoff point of 6 years based upon median disease duration of this OLP sample), both pain scale (VAS and NRS for pain) and total oral disease severity score (continuous variable) were entered into univariate and multivariate logistic regression, shown in Table 5. Due to collinearity of the VAS with NRS for pain $\left(r_{\text {spearman }}=0.96 ; P<0.0001\right)$, the VAS for pain was removed from the multivariate model as NRS was found to better correlate with the majority of studied variables (data not shown). 


\section{Prevalence and associated factors related to the presence of anxiety symptoms}

in patients with OLP.

The median score of HADS-A in the present population was 7 (IQR 3, 9). The prevalence of anxiety symptoms (determined by HADS-A score of $\geq 8$ ) in patients with OLP was $39.23 \%$ ( $n=102 ; 54(20.77 \%)$ with mild anxiety ( $8 \leq$ HADS-A $\leq 10), 40$ (15.38\%) with moderate anxiety ( $11 \leq$ HADS-A $\leq 15), 8(3.08 \%)$ with severe anxiety (HADS-A $\geq 16)$ ). Based on univariate analysis, younger age, Asian ethnicity, no alcohol consumption and those reporting higher levels of painful oral symptoms were significantly associated with the presence of anxiety symptoms in patients with OLP. There was no significant difference in the number of disease comorbidities and oral disease severity (based upon ODSS scores) between the anxious OLP group and non-anxious OLP group. After adjusting for other confounders in multivariate analysis, older ages (AOR: $0.96(0.94-0.99) ; p=0.004)$ were less likely to have symptoms of anxiety with OLP. On the contrary, anxiety symptoms were found to be independently and positively associated with history of smoking (AOR: $2.26(1.20-4.25) ; p=0.011$ ) and greater pain intensity (AOR: $1.29(1.12-1.50) ; p<0.000)$ in OLP patients (Table 5). The association of anxiety symptoms with Asian ethnicity and alcohol consumption in patients with OLP did not survive multivariate analysis but the positive association with having at least two disease comorbidities emerged (AOR: 2.78 (1.13-6.80); p $=0.025)$.

\section{Prevalence and associated factors related to the presence of depressive symptoms in patients with OLP.}

The median score of depressive symptoms using HADS-D in OLP patients was 4 (IQR 1, 6). Based upon cut-off HADS-D score of 8.0, the prevalence of depressive 
symptoms in OLP patients was $20.77 \%(n=54 ; 31$ (11.92\%) with mild depression (8

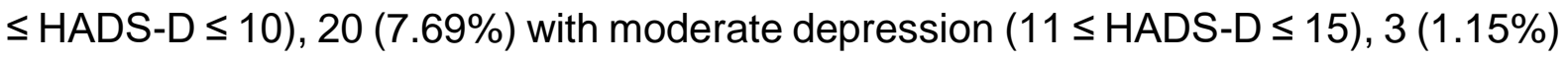
with severe depression (HADS-D $\geq 16)$ ). Univariate analysis demonstrated that Asian ethnicity, no alcohol consumption, having two disease comorbidities, greater oral pain and higher OLP disease severity were predictive factors for having depressive symptoms in the OLP patients. When potential confounders were controlled in multivariate models, those who have more than one disease comorbidity (AOR: 4.94 (1.34-18.14); $p=0.016)$ and reporting greater painful oral symptoms (AOR: 1.20 (1.01$1.44) ; p=0.041)$ remained significantly associated with an increased likelihood of having depressive symptoms in patients with OLP. Alcohol consumption was unexpectedly found to be a negative predictor of depressive symptoms (AOR: 0.19 (0.08-0.47), $\mathrm{p}<0.000)$. After adjusting for other confounders, there was no significant difference in Asian ethnicity and the degree of OLP disease severity between depressed and non-depressed OLP groups while the positive association between depressive symptoms and ever-smokers emerged (AOR: $2.56(1.16-5.66) ; p=0.02)$. (Table 5).

\section{Prevalence and associated factors related to the presence of psychological distress in patients with OLP.}

The median HADS-T score in the OLP sample was 10 (IQR 5, 16). Based on the HADS-T cut-off score of 15, Psychological distress was observed in $27.69 \%$ of patients with OLP $(n=55)$. In a univariate analysis, Asian ethnicity, alcohol consumption and greater intensity of oral pain were associated with distress in OLP patients. After confounders were adjusted, painful oral symptoms (AOR: 1.25 (1.061.47), $p=0.007$ ) remained independent predictors of distress in OLP, while OLP patients who were of older ages (AOR: 0.97 (0.94-0.99) and consumed alcohol (AOR: 
$0.35(0.18-0.69), p=0.002)$ had a significantly lower likelihood of emotional distress. the positive association between emotional distress and having at least two disease comorbidities emerged (AOR: 4.51 (1.49-13.68); $p=0.008)$. (Table 5). The remaining factors including history of smoking and severity of OLP were found not to be significant predictors after controlling for demographic and other OLP-related variables.

\section{Discussion}

The present study aimed to validate two commonly used psychological measures the Hospital Anxiety and Depression Scale and the 10-item Perceived Stress Scale in patients with OLP and is the first study examining their internal structures using CFA in this patient population. The present study results found that both the HADS and PSS-10 demonstrate a robust bifactor structure among patients with OLP, rather than their original models and other proposed models in the literature. This finding is consistent with recent validation studies of both scales in other medical conditions (lani, Lauriola, \& Costantini, 2014; C. P. Lee, Chou, Liu, \& Hung, 2017; Luciano, Barrada, Aguado, Osma, \& Garcia-Campayo, 2014; Norton et al., 2013; Perera et al., 2017; Reis, Lehr, Heber, \& Ebert, 2017). Though this bifactor model acknowledges the presence of two subscales within both measures, once the variance of the general factor of distress in the HADS and general factor of stress in the PSS-10 are controlled, subscale reliability coefficients $(\omega-h)$ do not reach the threshold necessary for a psychometrically meaningful interpretation. Hence both measures do not seem to have sufficient evidence supporting the utility of their subscale scores. As both scales are dominated by the presence of an underlying strong general factor, the HADS and PSS-10 should be employed as valid and reliable measures of overall psychological distress and perceived stress in patients with OLP, respectively. 
The measurement of psychological distress, as indicated by the use of the HADS total score, may be useful for patients with OLP when considering intervention for the management of concomitant anxiety and depression (e.g. cognitive behavioural therapy or certain classes of antidepressants) (Kroenke et al., 2016). Future studies of anxiety and depression in OLP should adopt other contemporary psychological instruments, such as the Generalised Anxiety Disorder Scale (GAD-7) and the Patient Health Questionnaire-9 (PHQ-9), as both scales were designed according to the Diagnostic and Statistical Manual of Mental Disorders, 5th ed (DSM-5) to aid screening and diagnosis of generalized anxiety disorders and major depressive disorders (Kroenke, Spitzer, Williams, Monahan, \& Lowe, 2007; Wittkampf et al., 2009). Further validation of GAD-7 and PHQ-9 in common oral mucosal diseases such as OLP is recommended.

The present study is the first prospective cross-sectional study with over 250 patients, providing the prevalence of psychological symptoms as well as examining the association of psychological comorbidities with various demographic and clinical variables in patients diagnosed with OLP in one tertiary Oral Medicine referral centre in the UK. The present findings revealed the prevalence of anxiety symptoms, depressive symptoms and emotional distress in OLP of $39.23 \%, 20.77 \%$ and $27.69 \%$, respectively. The reported prevalence of anxiety in OLP in this study was similar to the findings of a study of Croatian patients (Gavic, Cigic, Biocina Lukenda, Gruden, \& Gruden Pokupec, 2014); however, the present study found a much lower prevalence of depression (54.08\%) compared to the same study. The discrepancies in the prevalence figures between the two studies may be explained by the difference in the use of instruments measuring psychological comorbidities, the differences in ethnic 
and sociocultural background between the study populations, as well as variation in the methodological qualities of the different studies.

Notably, when considering anxiety and depression as comorbidities of OLP, the high prevalence of anxiety symptoms in the study OLP population led to this being the second most common comorbidity of oral lichen planus, after hypertension. Although the present study found a high prevalence of anxiety and depressive symptoms in this patient population, only $3.08 \%(8 / 260)$ and $5 \%(13 / 260)$ of patients had a definitive diagnosis of anxiety and depression, respectively, and were currently receiving antidepressant therapy. This means that a relatively high proportion of patients with OLP who have possible psychological comorbidities may not be aware of the associated symptoms and are not receiving optimal treatment or support. Screening for psychological comorbidities in patients with OLP using a psychometrically adequate outcome measures is therefore crucial in aiding identification of patients requiring additional psychological assessment and those who may benefit from appropriate psychological treatment and support, which could in turn improve their overall quality of life.

As expected, some demographic factors had certain roles in the presence of psychological comorbidities in patients with OLP. Regarding age, the present results found that younger patients were more likely to be anxious and have emotional distress than older patients. Although the present result is contradicted by one study (Vallejo et al., 2001), this finding is consistent with previous research regarding patients with cancer. This may be due to greater disruption to everyday living in younger aged patients, while the older age group may already have a certain degree of impairment of physical function, and may be cognitively and emotionally better prepared to accept and cope with illness (Linden, Vodermaier, Mackenzie, \& Greig, 
2012). Similar research in survivors of various types of cancers also added that this inverse association between age and psychological morbidities has been attributed by greater worries of recurrence and death in young patients (Hinz et al., 2009; Rogers et al., 2016), and we suggest that perhaps young patients with OLP may have greater concerns about potential transformation of OLP lesions into oral cancer.

OLP patients who currently smoke tobacco or previously smoked appeared to be more anxious or depressed than those who had never smoked, and this positive association between tobacco smoking and mental illness is generally in line with previously published research (Farrell et al., 1998). Interestingly, the present study demonstrated a decreased likelihood of having comorbid depression and emotional distress in OLP patients who consumed alcohol, and this finding was consistent with several studies supporting evidence of elevated risk of depression among alcohol abstainers. Some recent studies have suggested a curvi-linear J-shaped relationship between alcohol consumption and depression, indicating that non-drinkers and heavy drinkers have an increased risk of having depressive symptoms than light-to-moderate drinkers (Kim, Kim, Morris, \& Park, 2015; Skogen, Harvey, Henderson, Stordal, \& Mykletun, 2009). One possible explanation is that occasional alcohol drinking has a general protective influence with depressive symptoms which may be attributable to social circumstances surrounding drinking rather than the direct effect from alcohol intake itself, whilst some abstainers could have personal and social background characteristics such as poor social support, which predispose to depression and emotional distress (Rodgers, Parslow, \& Degenhardt, 2007).

The present study did not find an association between any of the psychological comorbidities and the clinical type, extent or severity of OLP lesions based on site and activity scores of ODSS. This finding is in keeping with several previous studies 
(Lopez-Jornet et al., 2016; Radwan-Oczko, Zwyrtek, Owczarek, \& Szczesniak, 2018; Shah, Ashok, \& Sujatha, 2009). In contrast, some previous studies have reported higher depression levels in patients with erosive OLP than in those with non-erosive lesions (Garcia-Pola \& Huerta, 2000; Rojo-Moreno et al., 1998; Vallejo et al., 2001). Another recent study observed significantly higher level of anxiety in OLP patients who had greater disease activity based upon ad hoc clinical disease activity scoring system (Zucoloto et al., 2019). The present findings, however, demonstrated that once variables including oral pain were controlled for in the multivariate model, the severity of clinical signs of OLP were found not to be risk predictors of depression and distress in OLP. This means that psychological symptoms can occur in patients with OLP regardless of the clinical type of disease and the severity of clinical signs. This may be partly due to the chronic, unpredictable, and potentially malignant nature of OLP, or the distress may even occur independently to OLP.

The present study demonstrated that significantly higher levels of painful oral symptoms were observed in a subgroup of OLP patients who had anxiety, depression or emotional distress than those without psychological comorbidities. This is in agreement with the body of evidence from a comprehensive review, which highlighted the strong and consistent association between somatic symptoms including pain across various chronic medical conditions and comorbid anxiety and depression (Katon, Lin, \& Kroenke, 2007). Psychological comorbidities may lead to heightened awareness of physical symptoms and the burden of symptoms and resulting functional impairment are likely to provoke or worsen episodes of anxiety and depression (Katon et al., 2007). Interestingly, research in other medical conditions found an association of anxiety and depression with poor adherence to self-care regimens, leading to repeated medication changes, continued escalation of medication regimens, and 
repeated diagnostic procedures including multiple biopsies. Recognition of the association between subjective symptoms of OLP and comorbid anxiety and depression should therefore be an important consideration in the management of patients with OLP.

A particular strength of this study is the sample size, which is notably larger than previous studies on psychological comorbidities in OLP. However, it should be noted that all the prevalence figures in this study may not reflect the true prevalence of psychological illnesses in patients with OLP, as these prevalence figures were estimated based on the HADS, which is a screening tool. The figures shown above may in fact be an overestimation or underestimation of the actual prevalence. Future prevalence studies of psychological comorbidities should use structural psychiatric interviews based upon the International Classification of Diseases (ICD-10) or the Diagnostic and Statistical Manual of Mental Disorders (DSM-5) to ensure definitive diagnoses of anxiety, depression and emotional distress are made. Information on socioeconomic status of participants including educational level, marital and job status as well as other variables such as sleep disturbance, which have been shown to be related to the development of psychological symptoms (Adamo et al., 2015), were not assessed in the present study. The measurement of subjective oral symptoms in the present study was recorded using both VAS and NRS, which measure overall symptom intensity alone. The incorporation of other self-report symptom instruments such as the short-form McGill Pain Questionnaire (SF-MPQ), which measures both quality and quantity of subjective symptoms, or the novel Oral Lichen Planus Symptom Severity Measure (OLP-SSM) would provide better profile of oral symptoms as reported by patients with OLP (Burke, Brennan, Ni Riordain, \& Madsen, 2019; Main, 2016). 
Regarding generalizability of the study results, the OLP sample in this study was based upon patients in one tertiary referral Oral Medicine centre, and thus may not represent the whole OLP population including asymptomatic cases of OLP who did not seek for professional treatment. The exclusion of non-English speakers may also reduce external validity of the study. In addition, given the nature of this crosssectional study, there is still no answer to the question as to whether OLP leads to the development of psychological morbidities or whether the opposite is true, or whether both conditions exacerbate each other in a cyclical relationship. Future prospective longitudinal studies are therefore of importance.

In conclusion, the present study suggests that the HADS and PSS-10 are appropriate to use as general measures of psychological distress and perceived stress in OLP patients. As approximately one third of patients with OLP have psychological comorbidities, it is important to assess the psychological status of all patients with this condition. The knowledge of demographic and clinical characteristics related to psychological comorbidities as shown in the present study, together with early recognition and management of changes in psychological status can facilitate clinicians in providing better holistic and long-term care in patients with this disorder.

\section{Author contributions}

Paswach Wiriyakijja and Richeal Ni Riordain designed the study. Paswach Wiriyakijja collected data from OLP patients, performed the statistical analyses reported in the study and wrote manuscript. Richeal Ni Riordain, Martina Shephard, Roddy McMillan, Tim Hodgson, Stefano Fedele and Stephen Porter edited and contributed comments on the manuscripts.

\section{Acknowledgements}


Paswach Wiriyakijja would like to thank Dr Emma Hayes, Dr Priya Thakrar, Dr Krupali

Patel, Dr Barbara Carey, Dr Carolina Venda Nova, Dr Craig Whitelaw, Dr Sanjeet Singhota and Dr Thomas Saunsbury for their substantial help and supports towards the recruitment process of the study and for reviewing and editing the manuscript. Paswach Wiriyakijja received a PhD Scholarship from the Faculty of Dentistry, Chulalongkorn University, Bangkok, Thailand. Stefano Fedele received funding from the National Institute for Health Research University College London Hospitals Biomedical Research Centre. The MEAN-IT study received service support funding from the National Institute for Health Research University College London Hospitals Biomedical Research Centre and the NIHR Clinical Research Network Portfolio.

\section{REFERENCES}

Adamo, D., Ruoppo, E., Leuci, S., Aria, M., Amato, M., \& Mignogna, M. D. (2015). Sleep disturbances, anxiety and depression in patients with oral lichen planus: a case-control study. J Eur Acad Dermatol Venereol, 29(2), 291-297. doi:10.1111/jdv.12525

Beauducel, A., \& Herzberg, P. Y. (2006). On the Performance of Maximum Likelihood Versus Means and Variance Adjusted Weighted Least Squares Estimation in CFA. Structural Equation Modeling: A Multidisciplinary Journal, 13(2), 186-203. doi:10.1207/s15328007sem1302_2

Bjelland, I., Dahl, A. A., Haug, T. T., \& Neckelmann, D. (2002). The validity of the Hospital Anxiety and Depression Scale. An updated literature review. J Psychosom Res, 52(2), 69-77.

Brunner, M., Nagy, G., \& Wilhelm, O. (2012). A tutorial on hierarchically structured constructs. J Pers, 80(4), 796-846. doi:10.1111/j.1467-6494.2011.00749.x

Burke, L. B., Brennan, M. T., Ni Riordain, R., \& Madsen, L. S. (2019). Novel Oral Lichen Planus Symptom Severity Measure for assessing patients' daily symptom experience. Oral Dis. doi:10.1111/odi.13109

Cerqueira, J. D. M., Moura, J. R., Arsati, F., Lima-Arsati, Y. B. O., Bittencourt, R. A., \& Freitas, V. S. (2018). Psychological disorders and oral lichen planus: A systematic review. J Investig Clin Dent, 9(4), e12363. doi:10.1111/jicd.12363

Chainani-Wu, N., Silverman, S., Jr., Reingold, A., Bostrom, A., Lozada-Nur, F., \& Weintraub, J. (2008). Validation of instruments to measure the symptoms and signs of oral lichen planus. Oral Surg Oral Med Oral Pathol Oral Radiol Endod, 105(1), 51-58. doi:10.1016/j.tripleo.2007.06.022

Cohen, S., Kamarck, T., \& Mermelstein, R. (1983). A global measure of perceived stress. J Health Soc Behav, 24(4), 385-396.

Cosco, T. D., Doyle, F., Ward, M., \& McGee, H. (2012). Latent structure of the Hospital Anxiety And Depression Scale: a 10-year systematic review. J Psychosom Res, 72(3), 180-184. doi:10.1016/j.jpsychores.2011.06.008 
Coyne, J. C., \& van Sonderen, E. (2012). No further research needed: abandoning the Hospital and Anxiety Depression Scale (HADS). J Psychosom Res, 72(3), 173-174. doi:10.1016/j.jpsychores.2011.12.003

Eisen, D. (2002). The clinical features, malignant potential, and systemic associations of oral lichen planus: a study of 723 patients. J Am Acad Dermatol, 46(2), 207-214.

Eisen, D., Carrozzo, M., Bagan Sebastian, J. V., \& Thongprasom, K. (2005). Number V Oral lichen planus: clinical features and management. Oral Dis, 11(6), 338-349. doi:10.1111/j.16010825.2005.01142.x

Escudier, M., Ahmed, N., Shirlaw, P., Setterfield, J., Tappuni, A., Black, M. M., \& Challacombe, S. J. (2007). A scoring system for mucosal disease severity with special reference to oral lichen planus. Br J Dermatol, 157(4), 765-770. doi:10.1111/j.1365-2133.2007.08106.x

Farrell, M., Howes, S., Taylor, C., Lewis, G., Jenkins, R., Bebbington, P., . . Meltzer, H. (1998). Substance misuse and psychiatric comorbidity: an overview of the OPCS National Psychiatric Morbidity Survey. Addict Behav, 23(6), 909-918.

Garcia-Pola, M. J., \& Huerta, G. (2000). Ansiety as an etiologic factor in oral lichen planus. Med Oral, 5(1), 7-13.

Gavic, L., Cigic, L., Biocina Lukenda, D., Gruden, V., \& Gruden Pokupec, J. S. (2014). The role of anxiety, depression, and psychological stress on the clinical status of recurrent aphthous stomatitis and oral lichen planus. J Oral Pathol Med, 43(6), 410-417. doi:10.1111/jop.12148

Giuliani, M., Troiano, G., Cordaro, M., Corsalini, M., Gioco, G., Lo Muzio, L., . . Lajolo, C. (2019). Rate of malignant transformation of oral lichen planus: A systematic review. Oral Dis, 25(3), 693709. doi:10.1111/odi.12885

Hinz, A., Krauss, O., Stolzenburg, J. U., Schwalenberg, T., Michalski, D., \& Schwarz, R. (2009). Anxiety and depression in patients with prostate cancer and other urogenital cancer: a longitudinal study. Urol Oncol, 27(4), 367-372. doi:10.1016/j.urolonc.2008.02.003

Hu, L.-t., \& Bentler, P. M. (1999). Cutoff criteria for fit indexes in covariance structure analysis: Conventional criteria versus new alternatives. Structural Equation Modeling, 6(1), 1-55. doi:10.1080/10705519909540118

Iani, L., Lauriola, M., \& Costantini, M. (2014). A confirmatory bifactor analysis of the Hospital Anxiety and Depression Scale in an Italian community sample. Health Qual Life Outcomes, 12, 84. doi:10.1186/1477-7525-12-84

Katon, W., Lin, E. H., \& Kroenke, K. (2007). The association of depression and anxiety with medical symptom burden in patients with chronic medical illness. Gen Hosp Psychiatry, 29(2), 147155. doi:10.1016/j.genhosppsych.2006.11.005

Kim, S. A., Kim, E., Morris, R. G., \& Park, W. S. (2015). Exploring the non-linear relationship between alcohol consumption and depression in an elderly population in Gangneung: the Gangneung Health Study. Yonsei Med J, 56(2), 418-425. doi:10.3349/ymj.2015.56.2.418

Kroenke, K., Spitzer, R. L., Williams, J. B., Monahan, P. O., \& Lowe, B. (2007). Anxiety disorders in primary care: prevalence, impairment, comorbidity, and detection. Ann Intern Med, 146(5), 317-325.

Kroenke, K., Wu, J., Yu, Z., Bair, M. J., Kean, J., Stump, T., \& Monahan, P. O. (2016). Patient Health Questionnaire Anxiety and Depression Scale: Initial Validation in Three Clinical Trials. Psychosom Med, 78(6), 716-727. doi:10.1097/psy.0000000000000322

Lee, C. P., Chou, Y. H., Liu, C. Y., \& Hung, C. I. (2017). Dimensionality of the Chinese hospital anxiety depression scale in psychiatric outpatients: Mokken scale and factor analyses. Int J Psychiatry Clin Pract, 21(4), 283-291. doi:10.1080/13651501.2017.1311350

Lee, E. H. (2012). Review of the psychometric evidence of the perceived stress scale. Asian Nurs Res (Korean Soc Nurs Sci), 6(4), 121-127. doi:10.1016/j.anr.2012.08.004

Linden, W., Vodermaier, A., Mackenzie, R., \& Greig, D. (2012). Anxiety and depression after cancer diagnosis: prevalence rates by cancer type, gender, and age. J Affect Disord, 141(2-3), 343351. doi:10.1016/j.jad.2012.03.025 
Lopez-Jornet, P., Cayuela, C. A., Tvarijonaviciute, A., Parra-Perez, F., Escribano, D., \& Ceron, J. (2016). Oral lichen planus: salival biomarkers cortisol, immunoglobulin A, adiponectin. J Oral Pathol Med, 45(3), 211-217. doi:10.1111/jop.12345

Luciano, J. V., Barrada, J. R., Aguado, J., Osma, J., \& Garcia-Campayo, J. (2014). Bifactor analysis and construct validity of the HADS: a cross-sectional and longitudinal study in fibromyalgia patients. Psychol Assess, 26(2), 395-406. doi:10.1037/a0035284

Main, C. J. (2016). Pain assessment in context: a state of the science review of the McGill pain questionnaire 40 years on. Pain, 157(7), 1387-1399. doi:10.1097/j.pain.0000000000000457

Millsap, R. E., \& Yun-Tein, J. (2004). Assessing Factorial Invariance in Ordered-Categorical Measures. Multivariate Behavioral Research, 39(3), 479-515. doi:10.1207/S15327906MBR3903_4

Mokkink, L. B., Terwee, C. B., Patrick, D. L., Alonso, J., Stratford, P. W., Knol, D. L., . . de Vet, H. C. (2010). The COSMIN study reached international consensus on taxonomy, terminology, and definitions of measurement properties for health-related patient-reported outcomes. J Clin Epidemiol, 63(7), 737-745. doi:10.1016/j.jclinepi.2010.02.006

Ni Riordain, R., Meaney, S., \& McCreary, C. (2011). Impact of chronic oral mucosal disease on daily life: preliminary observations from a qualitative study. Oral Dis, 17(3), 265-269. doi:10.1111/j.1601-0825.2010.01734.x

Nielsen, M. G., Ornbol, E., Vestergaard, M., Bech, P., Larsen, F. B., Lasgaard, M., \& Christensen, K. S. (2016). The construct validity of the Perceived Stress Scale. J Psychosom Res, 84, 22-30. doi:10.1016/j.jpsychores.2016.03.009

Norton, S., Cosco, T., Doyle, F., Done, J., \& Sacker, A. (2013). The Hospital Anxiety and Depression Scale: a meta confirmatory factor analysis. J Psychosom Res, 74(1), 74-81. doi:10.1016/j.jpsychores.2012.10.010

Perera, M. J., Brintz, C. E., Birnbaum-Weitzman, O., Penedo, F. J., Gallo, L. C., Gonzalez, P., . . Llabre, M. M. (2017). Factor structure of the Perceived Stress Scale-10 (PSS) across English and Spanish language responders in the HCHS/SOL Sociocultural Ancillary Study. Psychol Assess, 29(3), 320-328. doi:10.1037/pas0000336

Radwan-Oczko, M., Zwyrtek, E., Owczarek, J. E., \& Szczesniak, D. (2018). Psychopathological profile and quality of life of patients with oral lichen planus. J Appl Oral Sci, 26, e20170146. doi:10.1590/1678-7757-2017-0146

Reis, D., Lehr, D., Heber, E., \& Ebert, D. D. (2017). The German Version of the Perceived Stress Scale (PSS-10): Evaluation of Dimensionality, Validity, and Measurement Invariance With Exploratory and Confirmatory Bifactor Modeling. Assessment, 1073191117715731. doi:10.1177/1073191117715731

Rodgers, B., Parslow, R., \& Degenhardt, L. (2007). Affective disorders, anxiety disorders and psychological distress in non-drinkers. J Affect Disord, 99(1-3), 165-172. doi:10.1016/j.jad.2006.09.006

Rogers, Z., Elliott, F., Kasparian, N. A., Bishop, D. T., Barrett, J. H., \& Newton-Bishop, J. (2016). Psychosocial, clinical and demographic features related to worry in patients with melanoma. Melanoma Res, 26(5), 497-504. doi:10.1097/cmr.0000000000000266

Rojo-Moreno, J. L., Bagan, J. V., Rojo-Moreno, J., Donat, J. S., Milian, M. A., \& Jimenez, Y. (1998). Psychologic factors and oral lichen planus. A psychometric evaluation of 100 cases. Oral Surg Oral Med Oral Pathol Oral Radiol Endod, 86(6), 687-691.

Schellekens, M. P. J., van den Hurk, D. G. M., Prins, J. B., Molema, J., van der Drift, M. A., \& Speckens, A. E. M. (2016). The suitability of the Hospital Anxiety and Depression Scale, Distress Thermometer and other instruments to screen for psychiatric disorders in both lung cancer patients and their partners. J Affect Disord, 203, 176-183. doi:10.1016/j.jad.2016.05.044

Shah, B., Ashok, L., \& Sujatha, G. P. (2009). Evaluation of salivary cortisol and psychological factors in patients with oral lichen planus. Indian J Dent Res, 20(3), 288-292. doi:10.4103/09709290.57361 
Skogen, J. C., Harvey, S. B., Henderson, M., Stordal, E., \& Mykletun, A. (2009). Anxiety and depression among abstainers and low-level alcohol consumers. The Nord-Trondelag Health Study. Addiction, 104(9), 1519-1529. doi:10.1111/j.1360-0443.2009.02659.x

Tadakamadla, J., Kumar, S., Lalloo, R., \& Johnson, N. W. (2017). Qualitative analysis of the impact of Oral Potentially Malignant Disorders on daily life activities. PLoS One, 12(4), e0175531. doi:10.1371/journal.pone.0175531

Terwee, C. B., Bot, S. D., de Boer, M. R., van der Windt, D. A., Knol, D. L., Dekker, J., . . de Vet, H. C. (2007). Quality criteria were proposed for measurement properties of health status questionnaires. J Clin Epidemiol, 60(1), 34-42. doi:10.1016/j.jclinepi.2006.03.012

Vallejo, M. J., Huerta, G., Cerero, R., \& Seoane, J. M. (2001). Anxiety and depression as risk factors for oral lichen planus. Dermatology, 203(4), 303-307. doi:10.1159/000051777

van der Meij, E. H., \& van der Waal, I. (2003). Lack of clinicopathologic correlation in the diagnosis of oral lichen planus based on the presently available diagnostic criteria and suggestions for modifications. J Oral Pathol Med, 32(9), 507-512.

Wiriyakijja, P., Fedele, S., Porter, S. R., Mercadante, V., \& Ni Riordain, R. (2018). Patient-reported outcome measures in oral lichen planus: A comprehensive review of the literature with focus on psychometric properties and interpretability. J Oral Pathol Med, 47(3), 228-239. doi:10.1111/jop.12604

Wittkampf, K., van Ravesteijn, H., Baas, K., van de Hoogen, H., Schene, A., Bindels, P., . . van Weert, H. (2009). The accuracy of Patient Health Questionnaire-9 in detecting depression and measuring depression severity in high-risk groups in primary care. Gen Hosp Psychiatry, 31(5), 451-459. doi:10.1016/j.genhosppsych.2009.06.001

Zigmond, A. S., \& Snaith, R. P. (1983). The hospital anxiety and depression scale. Acta Psychiatr Scand, 67(6), 361-370.

Zinbarg, R. E., Revelle, W., Yovel, I., \& Li, W. (2005). Cronbach's $\alpha$, Revelle's $\beta$, and Mcdonald's $\omega H$ : their relations with each other and two alternative conceptualizations of reliability. Psychometrika, 70(1), 123-133. doi:10.1007/s11336-003-0974-7

Zucoloto, M. L., Shibakura, M. E. W., Pavanin, J. V., Garcia, F. T., da Silva Santos, P. S., Maciel, A. P., . . Motta, A. C. F. (2019). Severity of oral lichen planus and oral lichenoid lesions is associated with anxiety. Clin Oral Investig. doi:10.1007/s00784-019-02892-2 
Table 1 Descriptive item statistics, response distribution, skewness and kurtosis for each of the HADS and PSS-10 item

\begin{tabular}{|c|c|c|c|c|c|c|c|c|c|}
\hline \multirow{2}{*}{ Items } & \multirow{2}{*}{$\begin{array}{l}\text { med } \\
(I Q R)\end{array}$} & \multirow{2}{*}{$\begin{array}{c}\text { mean } \\
(\mathrm{SD})\end{array}$} & \multicolumn{5}{|c|}{ score distribution (\%) } & \multirow{2}{*}{ skewness } & \multirow{2}{*}{ kurtosis } \\
\hline & & & 0 & 1 & 2 & 3 & 4 & & \\
\hline \multicolumn{10}{|l|}{ HADS-anxiety } \\
\hline HA1 Tense-wound up & $1(1,2)$ & $\begin{array}{l}1.17 \\
(0.79)\end{array}$ & $\begin{array}{c}42 \\
(16.15)\end{array}$ & $\begin{array}{c}152 \\
(58.46)\end{array}$ & $\begin{array}{c}45 \\
(17.31)\end{array}$ & $\begin{array}{c}21 \\
(8.08)\end{array}$ & - & 0.66 & 3.27 \\
\hline HA3 Frightened feelings & $1(0,2)$ & $\begin{array}{l}0.98 \\
(0.92)\end{array}$ & $\begin{array}{c}98 \\
(37.69)\end{array}$ & $\begin{array}{c}84 \\
(32.31)\end{array}$ & $\begin{array}{c}64 \\
(24.64)\end{array}$ & $\begin{array}{c}14 \\
(5.38)\end{array}$ & - & 0.47 & 2.16 \\
\hline HA5 Worrying thought & $1(0,2)$ & $\begin{array}{l}1.1 \\
(0.93)\end{array}$ & $\begin{array}{c}76 \\
(29.23)\end{array}$ & $\begin{array}{c}107 \\
(41.15)\end{array}$ & $52(20)$ & $\begin{array}{c}25 \\
(9.62)\end{array}$ & - & 0.52 & 2.41 \\
\hline HA7 At ease-relaxed & $1(0,1)$ & $\begin{array}{l}0.89 \\
(0.75)\end{array}$ & $\begin{array}{c}84 \\
(32.31)\end{array}$ & $\begin{array}{c}126 \\
(48.46)\end{array}$ & $\begin{array}{c}45 \\
(17.31)\end{array}$ & $5(1.92)$ & - & 0.46 & 2.7 \\
\hline HA9 Butterflies in stomach & $1(0,1)$ & $\begin{array}{l}0.78 \\
(0.72)\end{array}$ & $\begin{array}{c}93 \\
(35.77)\end{array}$ & $\begin{array}{c}138 \\
(53.08)\end{array}$ & $21(8.08)$ & $8(3.08)$ & - & 0.84 & 3.97 \\
\hline HA11 Restless & $1(0,2)$ & $\begin{array}{l}1.02 \\
(0.87)\end{array}$ & $\begin{array}{c}82 \\
(31.54)\end{array}$ & $\begin{array}{c}105 \\
(40.38)\end{array}$ & $\begin{array}{c}59 \\
(22.69)\end{array}$ & $\begin{array}{c}14 \\
(5.38)\end{array}$ & - & 0.45 & 2.4 \\
\hline HA13 Sudden panic & $1(0,1)$ & $\begin{array}{l}0.83 \\
(0.79) \\
\end{array}$ & $\begin{array}{c}101 \\
(38.85)\end{array}$ & $\begin{array}{c}109 \\
(41.92)\end{array}$ & $\begin{array}{c}44 \\
(16.92)\end{array}$ & $6(2.31)$ & - & 0.6 & 2.65 \\
\hline \multicolumn{10}{|l|}{ HADS-depression } \\
\hline HA2 Enjoy things & $1(0,1)$ & $\begin{array}{l}0.68 \\
(0.70)\end{array}$ & $\begin{array}{c}114 \\
(43.85)\end{array}$ & $\begin{array}{c}118 \\
(45.38)\end{array}$ & $24(9.23)$ & $4(1.54)$ & - & 0.79 & 3.37 \\
\hline HA4 Laugh-see funny side & $0(0,1)$ & $\begin{array}{l}0.38 \\
(0.64)\end{array}$ & $\begin{array}{c}180 \\
(69.23)\end{array}$ & $\begin{array}{c}63 \\
(24.23)\end{array}$ & $14(5.38)$ & $3(1.15)$ & - & 1.69 & 5.59 \\
\hline HA6 Cheerful & $0(0,1)$ & $\begin{array}{l}0.57 \\
(0.71)\end{array}$ & $\begin{array}{c}142 \\
(54.62)\end{array}$ & $\begin{array}{c}92 \\
(35.38)\end{array}$ & $22(8.46)$ & $4(1.54)$ & - & 1.1 & 3.74 \\
\hline HA8 Slowed down & $1(1,2)$ & $\begin{array}{l}1.26 \\
(0.9)\end{array}$ & $\begin{array}{c}47 \\
(18.08)\end{array}$ & $\begin{array}{c}131 \\
(50.38)\end{array}$ & $\begin{array}{c}50 \\
(19.23)\end{array}$ & $\begin{array}{c}32 \\
(12.31)\end{array}$ & - & 0.51 & 2.58 \\
\hline HA10 Lost interest & $0(0,1)$ & $\begin{array}{l}0.57 \\
(0.80)\end{array}$ & $\begin{array}{c}157 \\
(60.38)\end{array}$ & $\begin{array}{c}63 \\
(24.23)\end{array}$ & $\begin{array}{c}35 \\
(13.46)\end{array}$ & $5(1.92)$ & - & 1.16 & 3.3 \\
\hline HA12 Excitement & $0(0,1)$ & $\begin{array}{l}0.64 \\
(0.83)\end{array}$ & $143(55)$ & $\begin{array}{c}79 \\
(30.38)\end{array}$ & $\begin{array}{c}27 \\
(10.38)\end{array}$ & $\begin{array}{c}11 \\
(4.23)\end{array}$ & - & 1.2 & 3.69 \\
\hline HA14 Enjoy leisures & $0(0,1)$ & $\begin{array}{l}0.34 \\
(0.64) \\
\end{array}$ & $\begin{array}{c}190 \\
(73.08)\end{array}$ & $\begin{array}{c}56 \\
(21.54) \\
\end{array}$ & $9(3.46)$ & $5(1.92)$ & - & 2.1 & 7.57 \\
\hline \multicolumn{10}{|l|}{ PSS-10 } \\
\hline P1 Upset & $2(1,3)$ & $\begin{array}{l}1.95 \\
(1.19)\end{array}$ & $\begin{array}{c}33 \\
(12.69)\end{array}$ & $\begin{array}{c}56 \\
(21.54)\end{array}$ & $\begin{array}{c}98 \\
(37.69)\end{array}$ & $\begin{array}{c}38 \\
(14.62)\end{array}$ & $\begin{array}{c}35 \\
(13.46)\end{array}$ & 0.13 & 2.32 \\
\hline P2 Life-uncontrollable & $2(1,2)$ & $\begin{array}{l}1.77 \\
(1.19)\end{array}$ & $\begin{array}{c}45 \\
(17.31)\end{array}$ & $\begin{array}{c}59 \\
(22.69)\end{array}$ & $\begin{array}{c}93 \\
(35.77)\end{array}$ & $\begin{array}{c}37 \\
(14.23)\end{array}$ & $26(10)$ & 0.19 & 2.31 \\
\hline P3 Nervous-stressed & $2(2,3)$ & $\begin{array}{l}2.16 \\
(1.09)\end{array}$ & $24(9.23)$ & $\begin{array}{c}37 \\
(14.23)\end{array}$ & $\begin{array}{c}102 \\
(39.23)\end{array}$ & $\begin{array}{c}68 \\
(26.15)\end{array}$ & $\begin{array}{c}29 \\
(11.15)\end{array}$ & -0.23 & 2.57 \\
\hline $\begin{array}{l}\text { P4 Ability to handle } \\
\text { problems }\end{array}$ & $1(0,2)$ & $\begin{array}{l}1.06 \\
(0.89)\end{array}$ & $\begin{array}{c}79 \\
(30.38)\end{array}$ & $\begin{array}{c}100 \\
(38.46)\end{array}$ & $\begin{array}{c}68 \\
(26.15)\end{array}$ & $\begin{array}{c}12 \\
(4.62)\end{array}$ & $1(0.38)$ & 0.42 & 2.5 \\
\hline P5 Things going your way & $1(1,2)$ & $\begin{array}{l}1.38 \\
(0.91)\end{array}$ & $\begin{array}{c}43 \\
(16.54)\end{array}$ & $\begin{array}{c}106 \\
(40.77)\end{array}$ & $\begin{array}{c}85 \\
(32.69)\end{array}$ & $\begin{array}{c}22 \\
(8.46)\end{array}$ & $4(1.54)$ & 0.35 & 2.88 \\
\hline P6 Unable to cope & $2(1,2)$ & $\begin{array}{l}1.56 \\
(1.08)\end{array}$ & $\begin{array}{c}46 \\
(17.69)\end{array}$ & $\begin{array}{c}83 \\
(31.92)\end{array}$ & $\begin{array}{c}85 \\
(32.89)\end{array}$ & $\begin{array}{c}32 \\
(12.31)\end{array}$ & $\begin{array}{c}14 \\
(5.38)\end{array}$ & 0.36 & 2.58 \\
\hline P7 Control irritations & $1(1,2)$ & $\begin{array}{l}1.24 \\
(0.92)\end{array}$ & $\begin{array}{c}62 \\
(23.85)\end{array}$ & $\begin{array}{c}97 \\
(37.31)\end{array}$ & $\begin{array}{c}79 \\
(30.38)\end{array}$ & $\begin{array}{c}21 \\
(8.08)\end{array}$ & $1(0.38)$ & 0.26 & 2.34 \\
\hline P8 On top of things & $1(1,2)$ & $\begin{array}{l}1.35 \\
(0.92)\end{array}$ & $\begin{array}{c}48 \\
(18.46)\end{array}$ & $\begin{array}{c}102 \\
(39.23)\end{array}$ & $\begin{array}{c}82 \\
(31.54)\end{array}$ & $26(10)$ & $2(0.77)$ & 0.26 & 2.52 \\
\hline P9 Angry & $2(1,3)$ & $\begin{array}{l}1.92 \\
(1.01)\end{array}$ & $20(7.69)$ & $\begin{array}{c}66 \\
(25.38)\end{array}$ & $\begin{array}{c}108 \\
(41.54)\end{array}$ & $\begin{array}{c}48 \\
(18.46)\end{array}$ & $\begin{array}{c}18 \\
(6.92)\end{array}$ & 0.12 & 2.69 \\
\hline P10 Difficulties-overloaded & $1(1,2)$ & $\begin{array}{l}1.49 \\
(1.14)\end{array}$ & $\begin{array}{c}56 \\
(21.54)\end{array}$ & $\begin{array}{c}83 \\
(31.92)\end{array}$ & $\begin{array}{c}76 \\
(29.23)\end{array}$ & $\begin{array}{c}27 \\
(10.38)\end{array}$ & $\begin{array}{c}18 \\
(6.92)\end{array}$ & 0.49 & 2.58 \\
\hline
\end{tabular}


Table 2 Confirmatory factor analysis model fit statistics

\begin{tabular}{lllll}
\hline & RMSEA & SRMR & CFI & TLI \\
\hline HADS & & & & \\
1-factor model & 0.111 & 0.069 & 0.936 & 0.925 \\
2-factor model & 0.07 & 0.049 & 0.975 & 0.97 \\
3-factor model & 0.065 & 0.047 & 0.979 & 0.974 \\
bifactor model & 0.051 & 0.035 & 0.989 & 0.984 \\
\hline PSS-10 & & & & \\
1-factor model & 0.155 & 0.05 & 0.947 & 0.932 \\
2-factor model & 0.112 & 0.035 & 0.973 & 0.964 \\
bifactor model & 0.076 & 0.021 & 0.991 & 0.984 \\
\hline
\end{tabular}


Table 3 Reliability estimates of overall and subscale scores of the HADS and PSS-10

\begin{tabular}{lccc}
\hline & Cronbach's $\alpha$ & McDonald's $\omega$ & $\omega-\mathrm{h}$ \\
\hline HADS-total (distress) & 0.9 & 0.966 & 0.838 \\
HADS-anxiety subscale & 0.87 & 0.91 & 0.275 \\
HADS-depression subscale & 0.84 & 0.974 & 0.164 \\
\hline PSS-total (stress) & 0.9 & 0.941 & 0.88 \\
PSS-perceived stress subscale & 0.89 & 0.933 & 0.031 \\
PSS-perceived self-efficacy subscale & 0.78 & 0.828 & 0.268 \\
\hline
\end{tabular}


Table 4 Descriptive statistics of demographics and OLP-related variables of study participants and bivariate analysis of factors associated with the presence of anxiety symptoms, depressive symptoms and psychological distress in patients with OLP $(\mathrm{N}=260)$

\begin{tabular}{|c|c|c|c|c|c|c|c|c|c|c|}
\hline Characteristics & $\begin{array}{l}\text { All subjects } \\
(\mathrm{N}=260)\end{array}$ & $\begin{array}{c}\text { HADS-A<8 } \\
(\mathrm{N}=158 \\
60.77 \%) \\
\end{array}$ & $\begin{array}{c}\text { HADS-A } \geq 8 \\
(\mathrm{~N}=102,39.23 \%)\end{array}$ & $\begin{array}{c}P \\
\text { value }\end{array}$ & $\begin{array}{c}\text { HADS-D<8 } \\
(\mathrm{N}=206,79.23 \%)\end{array}$ & $\begin{array}{c}\text { HADS-D } \geq 8 \\
(\mathrm{~N}=54,20.77 \%)\end{array}$ & $\begin{array}{c}\mathrm{P} \\
\text { value }\end{array}$ & $\begin{array}{c}\text { HADS-T<15 } \\
(\mathrm{N}=188,72.31 \%)\end{array}$ & $\begin{array}{c}\text { HADS-T } \geq 15 \\
(\mathrm{~N}=55,27.69 \%)\end{array}$ & $\begin{array}{c}P \\
\text { value }\end{array}$ \\
\hline \multicolumn{11}{|l|}{ Demographics } \\
\hline $\begin{array}{l}\text { Age (years): median (IQR) } \\
\text { Age (years): mean } \pm \text { SD } \\
\text { (range) }\end{array}$ & $\begin{array}{c}65.99(55.21,71.11) \\
63.32 \pm 11.22(27-88)\end{array}$ & $\begin{array}{c}67.63(58.45 \\
71.53)\end{array}$ & $\begin{array}{c}62.45(54.00 \\
69.52)\end{array}$ & $0.001^{a}$ & $\begin{array}{c}66.03(56.20 \\
70.70)\end{array}$ & $\begin{array}{c}65.95(54.30 \\
71.96)\end{array}$ & $0.821^{a}$ & $\begin{array}{c}66.78(56.78 \\
71.25)\end{array}$ & $\begin{array}{c}63.36(53.21 \\
70.01)\end{array}$ & $0.036^{a}$ \\
\hline Age group: $\mathrm{n}(\%)$ & & & & $0.003^{c}$ & & & $0.778^{b}$ & & & $0.103^{b}$ \\
\hline 25-44 (young adult) & $16(6.15)$ & $10(62.5)$ & $6(37.5)$ & & $14(87.5)$ & $2(12.5)$ & & $11(68.75)$ & $5(31.25)$ & \\
\hline 45-64 (middle aged) & $105(40.38)$ & $51(48.57)$ & $54(51.43)$ & & $82(78.1)$ & $23(21.9)$ & & $69(65.71)$ & 36 (34.29) & \\
\hline$\geq 65$ (elderly) & $139(53.46)$ & $97(69.78)$ & $42(30.22)$ & & $110(79.14)$ & $29(20.86)$ & & $108(77.7)$ & $31(22.3)$ & \\
\hline Gender (n, \%) & & & & $0.446^{c}$ & & & $0.760^{c}$ & & & $0.628^{c}$ \\
\hline Female & $208(80)$ & $124(59.62)$ & $84(40.38)$ & & $164(78.85)$ & $44(21.15)$ & & $149(71.63)$ & 59 (28.37) & \\
\hline Male & $52(20)$ & $34(65.38)$ & $18(34.62)$ & & $42(80.77)$ & $10(19.23)$ & & $39(75)$ & $13(25)$ & \\
\hline Ethnicity (n, \%) & & & & $0.170^{b}$ & & & $0.002^{b}$ & & & $0.000^{b}$ \\
\hline White & $183(70.38)$ & $119(65.03)$ & $64(34.97)$ & & $156(85.25)$ & $27(14.75)$ & & $146(79.78)$ & 37 (20.22) & \\
\hline Mixed & $6(2.31)$ & $3(50)$ & $3(50)$ & & $4(66.67)$ & $2(33.33)$ & & $4(66.67)$ & $2(33.33)$ & \\
\hline Asian & $62(23.85)$ & $31(50)$ & $31(50)$ & & $39(62.9)$ & $23(37.1)$ & & $33(53.23)$ & $29(46.77)$ & \\
\hline Black & $9(3.46)$ & $5(55.56)$ & $4(44.44)$ & & $7(77.78)$ & $2(22.22)$ & & $5(55.56)$ & $4(44.44)$ & \\
\hline \multicolumn{11}{|l|}{ Smoking (n, \%) } \\
\hline Non-smoker & $197(75.77)$ & $127(64.47)$ & 70 (35.53) & & $160(81.22)$ & $37(18.78)$ & & $146(74.11)$ & $51(25.89)$ & \\
\hline Ever smoker & $63(24.23)$ & $31(49.21)$ & $32(50.79)$ & $0.031^{c}$ & $46(73.02)$ & $17(26.98)$ & $0.162^{\mathrm{c}}$ & $42(66.67)$ & $21(33.33)$ & $0.25^{\mathrm{C}}$ \\
\hline Ex-smoker & $52(20)$ & $24(46.15)$ & $28(53.85)$ & $0.05^{\mathrm{b}}$ & $37(71.15)$ & $15(28.85)$ & $0.286^{b}$ & $33(63.46)$ & $19(36.54)$ & $0.235^{b}$ \\
\hline Current smoker & $11(4.23)$ & 7 (63.64) & $4(36.36)$ & & $9(81.82)$ & $2(18.18)$ & & $9(81.82)$ & $2(18.18)$ & \\
\hline \multicolumn{11}{|l|}{ Alcohol consumption ( $\mathrm{n}, \%)$} \\
\hline No & 85 (32.69) & $44(51.76)$ & $41(48.24)$ & & $53(62.35)$ & 32 (37.65) & & 47 (55.29) & $38(44.71)$ & \\
\hline Yes & $175(67.31)$ & $114(65.14)$ & $61(34.86)$ & $0.038^{c}$ & $153(87.43)$ & $22(12.57)$ & $0.000^{c}$ & $141(80.57)$ & $34(19.43)$ & $0.000^{c}$ \\
\hline$\leq 14$ Units/week & $150(57.69)$ & $98(65.33)$ & $52(34.67)$ & $0.106^{c}$ & $130(86.67)$ & 20 (13.33) & $0.000^{b}$ & $118(78.67)$ & 32 (21.33) & $0.000^{b}$ \\
\hline > 14 Units/week & $23(8.85)$ & $15(65.22)$ & $8(34.78)$ & & $21(91.30)$ & $2(8.7)$ & & $22(95.65)$ & $1(4.35)$ & \\
\hline Comorbidity (n, \%) & & & & $0.322^{\mathrm{c}}$ & & & $0.001^{b}$ & & & $0.021^{c}$ \\
\hline No & $39(15)$ & $26(66.67)$ & $13(33.33)$ & & 35 (89.74) & $4(10.26)$ & & 32 (82.05) & 7 (17.95) & \\
\hline 1 comorbidity & $65(25)$ & $43(66.15)$ & 22 (33.85) & & $59(90.77)$ & $6(9.23)$ & & $53(81.54)$ & $12(18.46)$ & \\
\hline$\geq 2$ comobidities & $156(60)$ & $89(57.05)$ & 67 (42.95) & & $112(71.79)$ & $44(28.21)$ & & $103(66.03)$ & $53(33.97)$ & \\
\hline
\end{tabular}


Table 4 Descriptive statistics of demographics and OLP-related variables of study participants and bivariate analysis of factors associated with the presence of anxiety symptoms, depressive symptoms and psychological distress in patients with OLP ( $\mathrm{N}=260)$ (cont.)

\begin{tabular}{|c|c|c|c|c|c|c|c|c|c|c|}
\hline Characteristics & $\begin{array}{l}\text { All subjects } \\
(\mathrm{N}=260)\end{array}$ & $\begin{array}{c}\text { HADS-A<8 } \\
(\mathrm{N}=158 \\
60.77 \%) \\
\end{array}$ & $\begin{array}{c}\text { HADS-A } \geq 8 \\
(\mathrm{~N}=102 \\
39.23 \%) \\
\end{array}$ & $P$ value & $\begin{array}{c}\text { HADS-D<8 } \\
(\mathrm{N}=206,79.23 \%)\end{array}$ & $\begin{array}{c}\text { HADS-D } \geq 8 \\
(\mathrm{~N}=54,20.77 \%)\end{array}$ & $P$ value & $\begin{array}{c}\text { HADS-T<15 } \\
(\mathrm{N}=188 \\
72.31 \%) \\
\end{array}$ & $\begin{array}{c}\text { HADS-T } \geq 15 \\
(\mathrm{~N}=55 \\
27.69 \%) \\
\end{array}$ & $P$ value \\
\hline $\begin{array}{l}\text { OLP-related variables } \\
\text { Disease duration (years), median } \\
\text { (IQR) }\end{array}$ & $6.37(2.83,10.84)$ & $\begin{array}{c}6.57(3.39 \\
11.35)\end{array}$ & $\begin{array}{c}6.14(2.44 \\
10.17)\end{array}$ & $0.396^{\mathrm{a}}$ & $6.47(3.20,11.1)$ & $\begin{array}{c}5.08(2.30 \\
9.35)\end{array}$ & $0.273^{\mathrm{a}}$ & $\begin{array}{c}6.62(3.18 \\
11.01)\end{array}$ & $\begin{array}{l}5.45(2.31 \\
10.03)\end{array}$ & $0.341^{\mathrm{a}}$ \\
\hline \multicolumn{11}{|l|}{ Predominant clinical types $(n, \%)$} \\
\hline Keratotic & $41(15.77)$ & $24(58.54)$ & $17(41.46)$ & $0.824^{c}$ & $35(85.37)$ & $6(14.63)$ & $0.547^{\mathrm{C}}$ & $30(73.17)$ & $11(26.83)$ & $0.986^{\mathrm{c}}$ \\
\hline Reticular & $30(11.54)$ & $16(53.33)$ & $14(46.67)$ & $0.807^{\mathrm{b}}$ & $25(83.33)$ & $5(16.67)$ & $0.493^{b}$ & $22(73.33)$ & $8(26.67)$ & $0.998^{\mathrm{b}}$ \\
\hline Plaque-like & $11(4.23)$ & $8(72.73)$ & $3(27.27)$ & & $10(90.91)$ & $1(9.09)$ & & $8(72.73)$ & $3(27.27)$ & \\
\hline Erythematous & $184(70.77)$ & $114(61.96)$ & $70(38.04)$ & & $143(77.72)$ & $41(22.28)$ & & $133(72.28)$ & $51(27.72)$ & \\
\hline Atrophic/Erosive & $116(44.62)$ & $72(62.07)$ & $44(37.93)$ & & $86(74.14)$ & $30(25.86)$ & & $83(71.55)$ & $33(28.45)$ & \\
\hline Desquamative gingivitis & $68(26.15)$ & $42(61.76)$ & $26(38.24)$ & & $57(83.82)$ & $11(16.18)$ & & $50(73.53)$ & $18(26.47)$ & \\
\hline Ulcerative & $35(13.46)$ & $20(57.14)$ & $15(42.86)$ & & $28(80)$ & $7(20)$ & & $25(71.43)$ & $10(28.57)$ & \\
\hline \multicolumn{11}{|l|}{ Pain scale: median (IQR) } \\
\hline VAS $(0-100 \mathrm{~mm})$ & $28(9,50)$ & $22(5,50)$ & $39(2,57)$ & $0.0008^{a}$ & $24(9,50)$ & $47(22,63)$ & $0.0008^{a}$ & $22(8,50)$ & $47(21,62)$ & $0.0002^{a}$ \\
\hline NRS $(0-10)$ & $3(1,5)$ & $3(1,5)$ & $4(2,6)$ & $0.0002^{a}$ & $3(1,5)$ & $5(3,7)$ & $0.0007^{a}$ & $3(1,5)$ & $5(3,7)$ & $0.0001^{a}$ \\
\hline \multicolumn{11}{|l|}{ ODSS: median (IQR) } \\
\hline ODSS-site & $6(4,8)$ & $6(4,8)$ & $6(3,8)$ & $0.954^{\mathrm{a}}$ & $6(3,8)$ & $6(4,9)$ & $0.216^{a}$ & $6(3.5,8)$ & $6(4,9)$ & $0.354^{\mathrm{a}}$ \\
\hline ODSS-activity & $6(3,11)$ & $6(3,10)$ & $7(2,11)$ & $0.552^{\mathrm{a}}$ & $6(2,10)$ & $8.5(4,11)$ & $0.052^{\mathrm{a}}$ & $6(3,10)$ & $\begin{array}{l}7(2.5,11) \\
19.5(10.5\end{array}$ & $0.243^{a}$ \\
\hline ODSS-total & $15(10,24)$ & $14(9,24)$ & $18(10,25)$ & $0.23^{\mathrm{a}}$ & $14.5(9,22)$ & $20(13,26)$ & $0.0163^{a}$ & $15(9,22)$ & $25.5)$ & $0.058^{a}$ \\
\hline \multicolumn{11}{|l|}{ Presence of extraoral LP (n, \%) } \\
\hline No & $189(72.69)$ & $116(61.38)$ & 73 (38.62) & & $153(80.95)$ & $36(19.05)$ & & $142(75.13)$ & $47(24.87)$ & \\
\hline Yes & $71(27.31)$ & $42(59.15)$ & $29(40.85)$ & $0.744^{\mathrm{C}}$ & $53(74.65)$ & $18(25.35)$ & $0.264^{c}$ & $46(64.79)$ & $25(35.21)$ & $0.097^{c}$ \\
\hline Yes/Genital area & $45(17.31)$ & $24(53.33)$ & $21(46.67)$ & $0.261^{\mathrm{C}}$ & $32(71.11)$ & $13(28.89)$ & $0.140^{c}$ & $28(62.22)$ & $17(37.78)$ & $0.096^{c}$ \\
\hline Yes/Skin & $37(14.23)$ & $22(59.46)$ & $14(40.54)$ & $0.86^{\mathrm{C}}$ & $28(75.68)$ & $9(24.32)$ & $0.565^{\mathrm{c}}$ & $25(67.57)$ & $12(32.43)$ & $0.487^{c}$ \\
\hline
\end{tabular}

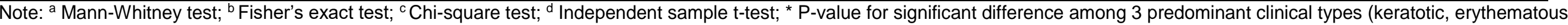

ulcerative); ${ }^{* \star} \mathrm{P}$-value for significant difference among 5 predominant clinical types (reticular, plaque-like, arothic/erosive, desquamative gingivitis, ulcerative) 
Table 4 Descriptive statistics of demographics and OLP-related variables of study participants and bivariate analysis of factors associated with the presence of anxiety symptoms, depressive symptoms and psychological distress in patients with OLP ( $\mathrm{N}=260)$ (cont.)

\begin{tabular}{|c|c|c|c|c|c|c|c|c|c|c|}
\hline Characteristics & $\begin{array}{l}\text { All subjects } \\
(\mathrm{N}=260)\end{array}$ & $\begin{array}{c}\text { HADS-A<8 } \\
(\mathrm{N}=158,60.77 \%)\end{array}$ & $\begin{array}{c}\text { HADS-A } \geq 8 \\
(\mathrm{~N}=102,39.23 \%)\end{array}$ & $P$ value & $\begin{array}{c}\text { HADS-D<8 } \\
(\mathrm{N}=206,79.23 \%)\end{array}$ & $\begin{array}{c}\text { HADS-D } \geq 8 \\
(\mathrm{~N}=54,20.77 \%)\end{array}$ & $P$ value & $\begin{array}{c}\text { HADS- } \mathrm{T}<15 \\
(\mathrm{~N}=188,72.31 \%)\end{array}$ & $\begin{array}{c}\text { HADS- } \mathrm{T} \geq 15 \\
(\mathrm{~N}=55,27.69 \%)\end{array}$ & $P$ value \\
\hline \multicolumn{11}{|c|}{ OLP-related variables (cont.) } \\
\hline Treatment $(\mathrm{n}, \%)$ & & & & $0.754^{b}$ & & & $0.102^{b}$ & & & $0.887^{b}$ \\
\hline No Tx/Tanes & $34(13.08)$ & $23(67.65)$ & $11(32.35)$ & & $31(91.18)$ & $3(8.82)$ & & $26(76.47)$ & $8(23.53)$ & \\
\hline TCS alone & $164(63.08)$ & $98(59.76)$ & $66(40.24)$ & & $130(79.27)$ & $34(20.73)$ & & $119(72.56)$ & $45(27.44)$ & \\
\hline TCS with other topical Tx & $52(20)$ & $30(57.69)$ & $22(42.31)$ & & $39(75)$ & $13(25)$ & & $36(69.33)$ & $16(30.77)$ & \\
\hline Topical and systemic Tx & $10(3.85)$ & $7(70)$ & $3(30)$ & & $6(60)$ & $4(40)$ & & $7(70)$ & $3(30)$ & \\
\hline \multicolumn{11}{|l|}{ Psychological outcomes } \\
\hline \multicolumn{11}{|l|}{ Anxiety scale: med (IQR) } \\
\hline HADS-A & $7(3,9)$ & & & & $6(3,8)$ & $11(8,14)$ & $0.0000^{a}$ & & & \\
\hline \multicolumn{11}{|l|}{ Depression scale: med (IQR) } \\
\hline HADS-D & $4(1,6)$ & $2(1,4)$ & $6(4,10)$ & $0.0000^{a}$ & & & & & & \\
\hline \multicolumn{11}{|l|}{ Distress scale: med (IQR) } \\
\hline HADS-T & $10(5,16)$ & & & & & & & & & \\
\hline \multicolumn{11}{|c|}{ Stress scale: mean \pm SD (range) } \\
\hline PSS-10 & $\begin{array}{c}15.87 \pm 7.63(0- \\
34)\end{array}$ & $\begin{array}{c}12.35 \pm 6.33 \\
(95 \% \mathrm{Cl}=11.35- \\
13.34)\end{array}$ & $\begin{array}{c}21.32 \pm 6.14 \\
(95 \% \mathrm{Cl}=20.12- \\
22.53)\end{array}$ & $0.0000^{d}$ & $\begin{array}{c}14.07 \pm 6.91 \\
(95 \% \mathrm{Cl}=13.12- \\
15.02)\end{array}$ & $\begin{array}{c}22.72 \pm 6.28 \\
(95 \% \mathrm{Cl}=21.01- \\
24.44)\end{array}$ & $0.0000^{d}$ & $\begin{array}{c}12.90 \pm 6.31 \\
(95 \% \mathrm{Cl}=12.00- \\
13.81)\end{array}$ & $\begin{array}{c}23.61 \pm 4.85 \\
(95 \% \mathrm{Cl}=22.45- \\
24.75)\end{array}$ & $0.0000^{d}$ \\
\hline
\end{tabular}

Note: ${ }^{a}$ Mann-Whitney test; ${ }^{\mathrm{b}}$ Fisher's exact test; ${ }^{\mathrm{c}}$ Chi-square test; ${ }^{\mathrm{d}}$ Independent sample t-test; TCS $=$ topical corticosteroids; Tanes $=$ topical anesthetic agents 
Table 5 Univariate and multivariate logistic regression of factors associated with the presence of anxiety symptoms, depressive symptoms and psychological distress in patients with OLP $(\mathrm{N}=210)$

\begin{tabular}{|c|c|c|c|c|c|c|c|c|c|c|c|c|}
\hline \multirow[b]{2}{*}{ Variables } & \multicolumn{4}{|c|}{ Presence of anxiety symptoms (HADS-A $\geq 8$ ) } & \multicolumn{4}{|c|}{ Presence of depressive symptoms (HADS-D $\geq 8$ ) } & \multicolumn{4}{|c|}{ Presence of psychological distress (HADS-D $\geq 15$ ) } \\
\hline & Crude OR $[95 \% \mathrm{Cl}]$ & $\begin{array}{l}\mathrm{P} \text { - } \\
\text { value }\end{array}$ & Adj-OR [95\%Cl] & $\begin{array}{l}\mathrm{P} \text { - } \\
\text { value }\end{array}$ & $\begin{array}{l}\text { Crude OR } \\
{[95 \% \mathrm{Cl}]} \\
\end{array}$ & $\begin{array}{l}\mathrm{P} \text { - } \\
\text { value }\end{array}$ & Adj-OR $[95 \% \mathrm{Cl}]$ & $\begin{array}{l}\mathrm{P} \text { - } \\
\text { value }\end{array}$ & $\begin{array}{l}\text { Crude OR } \\
{[95 \% \mathrm{CI}]} \\
\end{array}$ & $\begin{array}{l}\mathrm{P} \text { - } \\
\text { value }\end{array}$ & Adj-OR [95\%Cl] & $\begin{array}{l}\mathrm{P} \text { - } \\
\text { value }\end{array}$ \\
\hline \multicolumn{13}{|l|}{ Demographic variable } \\
\hline Age & $0.97[0.95-0.99]$ & 0.007 & $0.96[0.94-0.99]$ & 0.004 & 1 [0.98-1.03] & 0.776 & 1 [0.96-1.03] & 0.832 & $0.98[0.95-1.00]$ & 0.055 & $0.97[0.94-0.99]$ & 0.021 \\
\hline \multicolumn{13}{|l|}{ Ethnicity (white = ref.) } \\
\hline Mixed & $1.86[0.36-9.48]$ & 0.455 & $\begin{array}{l}2.00[0.35- \\
11.54]\end{array}$ & 0.436 & $2.89[0.5-16.56]$ & 0.234 & $6.97[0.79-61.92]$ & 0.081 & $1.97[0.35-17.13]$ & 0.443 & $2.88[0.40-20.55]$ & 0.29 \\
\hline Black & $1.49[0.39-5.73]$ & 0.564 & $0.73[0.16-3.31]$ & 0.687 & $1.65[0.33-8.37]$ & 0.545 & $0.60[0.10-3.72]$ & 0.58 & $3.16[0.81-12.34]$ & 0.098 & $1.38[0.30-6.42]$ & 0.677 \\
\hline Ever smoker (non-smoker = ref.) & $1.87[1.06-3.32]$ & 0.032 & $2.26[1.20-4.25]$ & 0.011 & $1.60[0.82-3.1]$ & 0.165 & $2.56[1.16-5.66]$ & 0.02 & $1.43[0.78-2.64]$ & 0.252 & $2.02[0.99-4.13]$ & 0.053 \\
\hline Alcohol consumption (non-drinkers $=$ ref.) & $0.57[0.34-0.97]$ & 0.039 & $0.59[0.32-1.10]$ & 0.097 & $0.24[0.13-0.45]$ & 0 & $0.26[0.12-0.53]$ & 0 & $0.30[0.17-0.53]$ & 0 & $0.35[0.18-0.69]$ & 0.002 \\
\hline \multicolumn{13}{|l|}{ Comorbidity (no = ref.) } \\
\hline 1 comorbidity & $1.02[0.44-2.37]$ & 0.957 & $1.52[0.59-3.91]$ & 0.798 & $0.89[0.23-3.37]$ & 0.864 & $\begin{array}{l}1.10[0.25-4.90] \\
4.94[1.34-\end{array}$ & 0.874 & $1.04[0.37-2.90]$ & 0.948 & $\begin{array}{l}1.64[0.50-5.41] \\
4.51[1.49-\end{array}$ & 0.63 \\
\hline$\geq 2$ comobidities & $1.51[0.72-3.15]$ & 0.277 & $2.78[1.13-6.80]$ & 0.025 & $3.44[1.15-10.24]$ & 0.027 & 18.14] & 0.016 & $2.35[0.97-5.68]$ & 0.057 & 13.68] & 0.008 \\
\hline NRS for pain score & $1.22[1.10-1.36]$ & 0 & $1.29[1.12-1.50]$ & 0 & $1.26[1.11-1.43]$ & 0 & $1.20[1.01-1.44]$ & 0.041 & 1.27 [1.13-1.43] & 0 & $1.25[1.06-1.47]$ & 0.007 \\
\hline Disease severity score (ODSS-total) & 1.01 [0.99-1.03] & 0.449 & 0.97 [0.94-1.01] & 0.063 & $1.03[1-1.06]$ & 0.034 & 0.99 [0.95-1.03] & 0.651 & $1.02[1-1.05]$ & 0.075 & $0.98[0.95-1.02]$ & 0.293 \\
\hline
\end{tabular}

